\title{
Self Confidence and the Cognitive Styles among the Secondary School Students in Sri Lanka
}

\author{
Liyadipita L.A.M.H.P. \\ Faculty of Humanities, University of Kelaniya, Sri Lanka \\ hansaniliyadipita@yahoo.com
}

\begin{abstract}
The purpose of this study was to determine secondary school students' self-confidence in terms of cognitive style. The dependent variable was self-confidence and independent factors were gender and cognitive styles. The study used a descriptive survey and the sample consisted of 400 students in grade 11. Data was collected using the Cognitive Style Inventory and the Self-confidence Inventory and was analyzed using a two-way ANOVA. Data were analyzed using Two Way ANOVA with a 52-factorial design. The most important influence of cognitive style and gender on secondary school pupils' self-confidence was shown to be substantial. The double interaction impact of cognitive style and gender on secondary school students' self-confidence was discovered to be substantial. School teachers should organize classes by employing active teaching strategies, suitable teaching tactics, and aiding students in developing academic self-confidence. Lectures, workshops, and seminars should be provided to students who are falling behind owing to poor cognitive style selection.
\end{abstract}

Keywords: Self-Confidence, Gender, Cognitive Style, Secondary School Students

Copyright: (C) 2021 Liyadipita, L.A.M.H.P. This is an open access article distributed under the Creative Commons Attribution License, which permits unrestricted use, distribution, and reproduction in any medium, provided the original work is properly cited.

Correspondence: hansaniliyadipita@yahoo.com

ORCID of authors: Liyadipita L.A.M.H.P.: https://orcid.org/0000-0001-6777-640X

DOI: http://doi.org/10.4038/kjm.v10i0.7683 


\section{Introduction}

Human actions can be classified into three main categories: cognition, affection, and conation. The mental processes involved in obtaining information and comprehension are referred to as cognition. Thinking, knowing, remembering, judging, and problem-solving are examples of cognitive processes. These are higher-order brain processes that include language, creativity, perception, planning, and knowledge growth in youngsters, and they are also necessary for survival. Animals employ strategies like camouflage, speed, and others to adapt to changing environmental conditions. For providing quality and standard education, the instructor or the teacher must know the needs of students; every child comes with some inner qualities and abilities and differentiate the child from the others.

Every student has a different technique to gathering and processing data, which is referred to as "their own style." Environmental variables help to develop such talents, which are not established at birth. The relationship between the learner's qualities and the topic, technique, and media of instruction helps to ensure that the teaching-learning process is extremely successful. In the academic setting, a variety of single aspects enhance learning and performance. The learners' cognitive styles should also be taken into account. The term "cognitive style" refers to a hypothetical construct that has been created to describe the process of mediating inputs and responses(Messick, 1976, P.06). The cognitive style is often described as "organising and digesting information." It was recently characterised as "individual variations in processing essentially connected to a person's cognitive style; they represent a person's preferred manner of processing; they are partly fixed, reasonably stable, and potentially innate preferences" (Peterson, Rayner, \& Armstrong, 2009, P.199-208). As a result, the researchers focus on the students' cognitive styles and self-confidence.

\section{Literature Review}

Cognitive Style refers to the features in which the individuals theoretically organize and manage the environment. The studies that explore the cognitive style concept concluded that students' cognitive styles are stable characteristics (Riding \& Pearson, 1994) \& Riding \& Sadler-

Smith, 1997), which links across various contexts and that it is not likely to change based on a specific learning platform. The following are some assumptions related to cognitive style.

- It is consistent across time

- It is concerned with the form rather than the substance of information processing

- It may be value differentiated (i.e. styles describe "different" rather than "better" thinking processes) (Sadler-Smith and Badger, 1998)

- It is a widespread factor that may be measured using psychometric methods.

- It's a bipolar

Previous information, socio-economic status, thinking, attitude, and intelligence, etc. are some factors affected by the cognitive styles. One of the most highlighted improvements in the education system can be seen from the amount of research done in the area of cognitive style which recognizes that the students in classrooms have vivid differences in their cognitive style. To this teaching and learning process, the instructors and learners need to understand better and appreciate these individual differences and how they affect the learning process. This is a continuous process. Understanding individual cognitive style preferences has significant implications for learners: It helps the students to be aware of 
their abilities, how they learn, themselves, why they differ from peers and how they think about the environment. Further, it assists them in planning their learning and developing strategies that bridge with different learning environments to make learning more meaningful and effective. This awareness has positive psychological effects for learners and they can obtain selfesteem, motivation, and feel more confident about themselves (Sarasin, 2006). Many researches have been conducted on cognitive style with different variables. Pitta-Pantazi and Christou (2009) said that spatial-imagery cognitive style is related to originality, mathematical fluency, and flexibility. Kozhevnikov et al. (2002) highlights that visual-spatial imagery is very useful for mathematics and that spatial imagery is an important factor of high mathematic cal achievement in a students' life.

Navarro et al. (1999) said that field of independence style was related to achievement in arithmetic. Jantan (2014) spot out the positive correlation between students' cognitive styles and their mathematics achievement in the learning process. Singh (2015) found that there is no specific relationship between academic achievement in mathematics and hemispheric dominance. Rao (2014) analyzed that the highlighted differences in mean scores of mathematics achievement between the field-dependent and fieldindependent students. Jena (2013) examined the cognitive style of secondary school students in gender and stream. Singh (2017) highlighted that there is a specific bond between learning style, cognitive style, and academic achievement of secondary school students. Beri and Kumar (2016) inspected the cognitive style of secondary school students based on adversity quotient. Cognitive Style has a significant effect on mathematics. Parashar, Aggarwal (2013) identified that cognitive style plays a significant role in the self-confidence.
According to the review of literature, it shows that during the last two decades, a few researches have been done in the cognitive style learning in different contexts. Further, it reveals that researches in the field of selfconfidence are also improving fast touching many new areas. These researches do not study the interaction effects of cognitive style and gender on self-confidence. This research work is an attempt to investigate the main and interaction effects of cognitive style and gender on the self-confidence of secondary school students in Sri Lanka. The following were the variables involved in the study.

Dependent Variable of the study was "SelfConfidence" and the independent variable was the Cognitive Style (Integrated style, Intuitive style, Split style, Systematic style and Undifferentiated style) and Gender (Male \& Female).

\section{Objectives of the study}

To examine the effect of (a) cognitive style and (b) gender on the self-confidence of school students.

To find out the interaction effect of cognitive style and gender on the self-confidence of school students.

\section{Development of Hypotheses}

H01: There exists no significant effect of (a) cognitive style and (b) gender on the selfconfidence of school students.

H02: There exists no significant interaction effect of cognitive style and gender on the self-confidence of school students.

\section{Methodology}

A descriptive survey method was used for the study and a multistage random sampling technique was used to select the sample of 
400 secondary school students from the Welimada Educational Zone. The sample was additionally categorized on the basis of their cognitive style and gender. The norms are given in manual the students who scored above 81 on systematic style and below on 61 on intuitive style were treated as systematic cognitive style. Accordingly, the students who scored below 61 on systematic style and above 81 on intuitive style were classified as intuitive cognitive style. Also, the students who scored above 81 on both the style; systematic and intuitive were considered as integrated cognitive styles. The students who scored on medium-high were categorized as "split-cognitive style". The inventory included 60 statements under the main nine areas which pertain to study the self-confidence among the students. There is no time limit for the study. And nine areas of the inventory are (a) Social and Emotional Matureness (b) Intellectual Adequateness (c) satisfaction (d) Optimismness (e) Independentness (f) SelfAssuredness (g) Self-Feelingness (h) Evaluation about himself (I) Decisiveness.

The Test-retest technique and the Split-half method were both used to determine the inventory's dependability. The inventory's reliability coefficients were 0.89 and 0.88 . The inventory has sufficient validity with other comparable inventories and associated measures by other authors, in addition to having good face validity. The researcher utilised a Likert type five-point scale to assess school pupils' cognitive styles. The 40 assertions are about the five various sorts of cognitive styles that pupils have, such as Integrated Style, Intuitive Style, Split Style, Systematic Style, and Undifferentiated Style. The S-curve was used to calculate the inventory's reliability coefficients. Reliability coefficients for the inventory were determined by the Split-half method and the Test-retest method. The reliability coefficients of the inventory were 0.65 and 0.39. CSI has a fair degree of concurrent validity, as evidenced by the correlation coefficients of 0.262 . The data was analysed using descriptive and inferential statistics approaches. The major impacts of cognitive style and gender on secondary school students' self-confidence were investigated using the two-way ANOVA method with the 52 factorial design in SPSS. Before using Two-Way ANOVA, Levene's Evaluate of Homogeneity of Variance was performed to test the assumption of homogeneity of variance. When the F-value was determined to be significant, the study was further investigated using the t-test.

\section{Findings and Discussion}

The first and foremost objective of the current study was to find out the interaction effects of cognitive style and gender on the self-confidence of school students. The independent variables; cognitive style and gender were coded as A and B respectively and were varied into two ways as: Integrated Style (A1), Intuitive Style (A2), Split Style (A3), Systematic Style (A4) and Undifferentiated Style (A5) and Male (B1) $\&$ Female (B2). Means and SDs of different sub-samples have been presented in the Table 1 (Appendix A) and Figure 1 (Appendix E ) The finding summary of ANOVA $(5 \times 2)$ has also been represented in Table 2 (Appendix B), which is analyzed in the main effects and interaction effects.

\section{ain Effects of Cognitive Style and Gender on Self-Confidence of Secondary School Students Cognitive Style (A)}

From the Table 2 (Appendix B) that F-ratio (5.16) for the main effect of cognitive style on the self-confidence of school students is significant at 0.01 level that emphasizes the cognitive style has a noteworthy effect on the self-confidence of secondary school students in the Welimada Educational Zone. So, the null hypothesis that was taken by the researcher; H01 (a), "There exist no significant effect of cognitive style on the self-confidence of secondary school students" is not retained. To investigate 
further, the ' $\mathrm{t}$ ' -value has been given in the Table 3 (Appendix C).

Table 3 (Appendix C) defines that t-value (2.02) for students having integrated style and for students appropriating to intuitive style is significant at 0.05 levels. The mean scores for students with integrated style (26.08) were found to be higher selfconfidence than the students with intuitive style. Further, it can be spot out from Table 3(Appendix C) that the students with integrated styles have higher self-confidence than the students having split styles in their academic performances. The t-value (0.77) vides Table 3 (Appendix $C$ ) indicates that there is no significant difference in selfconfidence between students having integrated style and systematic style. When comparing the mean scores, it can be reduced that students who were having an integrated style reported lower selfconfidence than students belonging to systematic style. This was one of the best findings in the study.

When we consider about the Table 3 (Appendix C), it further discusses that the mean scores of self-confidence of students having integrated style and students belonging undifferentiated style do not have a different in significantly but the students who have integrated style possess significantly higher self-confidence than the students belonging undifferentiated style in the context. Similarly, the t-value of (0.66) from Table 3 (Appendix C) for students having intuitive style and for students having split style was not reported to be very significant at 0.01 level. Conversely, the tvalue (2.73) from Table 3 (Appendix C) between the students having intuitive style and for students belonging systematic style is significantly highlighted at 0.01 levels. From the analysis of mean scores of the study, it can be decided that students having systematic style were found to possess significantly higher self-confidence than the students belonging intuitive style.
As shown in Table 3 (Appendix C) it can be simply observed to anyone that the mean scores of self-confidences of students in the school context were having intuitive style and for students having undifferentiated style do not differ significantly. Further, the students having undifferentiated styles have marginally higher self-confidence than their counterparts of the study. According to table 3 (Appendix C), it highlights that students having split style and students having systematic style differ significantly about the self-confidence of the students. But the students having split styles have significantly lower self-confidence than the students belonging systematic style. The tvalue (0.52) for students belonging split style and students having undifferentiated style are found no significant at 0.01 level. Furthermore, it is portrayed in the same table that the t-value of (2.64) for students having systematic style and for students having undifferentiated style is found to be significant at 0.01 level and the final group is better than the former one concerning their self-confidence. In Figure 2 (Appendix F), it has been illustrated the mean for the main effect of cognitive style on self-confidence.

Table 2 (Appendix B) shows that the F-ratio of (7.07) for the main effect of gender on the self-confidence of school students is significant at 0.01 levels leading to the inference that gender has a significant main effect on the self-confidence of secondary school students. So, the null hypothesis H01 (b), "There exists no significant effect of gender on the self-confidence of secondary school students" is not retained. According to the study, Male students have high performance on self-confidence than female students in the school context.

\section{Gender on Self- Confidence of and Double Interaction Effects of Cognitive Style Secondary School Students Cognitive Style (A) x Gender (B)}

Table 2 (Appendix B) highlights the double interaction effect between cognitive style 
and gender is (2.55) which is significant at 0.05 level leading to the inference that cognitive style and gender interact with each other in relation to the self-confidence of secondary school students in Welimada Educational Zone. Accordingly, the null hypothesis H02, “There exists no significant interaction effect of cognitive style and gender on the self-confidence of secondary school students" is not retained. It can be concluded that there is a momentous interaction effect of cognitive style and gender on the self-confidence of secondary school students. Further, it is subjected to ttest computation to find out the significant difference between the mean scores of selfconfidences of different groups for cognitive style and gender. The results in table 4 (Appendix D) confirm the above statement.

Table 4 (Appendix D) shows the t-value (2.19) for male students who own to integrated style (A1B1) and for female students belonging to integrated style (A1B2) is highly depicted at 0.05 levels. Therefore it may be contingent from the mean scores than female students having integrated style (A1B2) have a higher (24.08) self-confidence than the male students having an integrated style in a school. Male students having an integrated style (A1B1) and for male students having intuitive style (A2B1) do not differ significantly with respect to their selfconfidence scores too. When comparing of mean scores, it can be deduced that male students having intuitive style (A2B1) have a higher self-confidence (25.89) than male students having integrated style (A1B1) In the same way, female students having intuitive style (A2B2) have significantly a higher self-confidence (30.48) than the male students having integrated style (A1B1). Conversely, t-value (2.12) Table 4 (Appendix D) for male students having integrated style (A1B1) is significant at 0.05 levels. An analysis of the mean scores makes it clear that male students having split style (A3B1) (20.28) possess higher selfconfidence than that of male students having integrated style (A1B1). It can also be inferred that male student who have integrated style (A1B1) and female students who have split-style (A3B2) do not differ significantly with respect to self-confidence. This is also one of the great findings of this study.

Table 4 (Appendix D) shows that t-value (2.08) for male students having integrated style (A1B1) and for male students having systematic style (A4B1) is significant at 0.05 levels. Also from the mean scores, it explains the male students belonging systematic style (A4B1) possess significantly higher self-confidence (20.28) than the male students have integrated style (A1B1). Table 4 (Appendix D) reveals that ' $t$ '-values for the groups namely A1B1 vs. $\mathrm{A} 4 \mathrm{~B} 2, \mathrm{~A} 1 \mathrm{~B} 1$ vs. A5B1, A1B2 vs. A2B1, $\mathrm{A} 1 \mathrm{~B} 2$ vs. $\mathrm{A} 2 \mathrm{~B} 2, \mathrm{~A} 1 \mathrm{~B} 2$ vs. A3B1, A1B2 vs. $\mathrm{A} 3 \mathrm{~B} 2, \mathrm{~A} 1 \mathrm{~B} 2$ vs. A4B1 were found to be non- significant while on comparison of mean scores, A1B2 possessed high selfconfidence than their counterparts and tvalue (2.07) for male students having integrated style (A1B1) and for female students having undifferentiated style (A5B2) differ significantly (33.40) high selfconfidence than the former counterparts. Actually, a significant difference was identified in self-confidence between female students having a systematic style (A4B2) and female students having integrated style (A1B2).

Further, the table 4 (Appendix D) shows that the mean scores of self-confidence of female students having integrated style (A1B2) and for male students having undifferentiated style (A5B1) do not differ significantly in the studied context. But, Table 4 (Appendix D) justifies that mean scores of selfconfidence of female students having integrated style (A1B2) and for female students having undifferentiated style (A5B2) differ significantly and have significantly higher self-confidence than the previous one. The table 4 (Appendix D) Further examines the t-values for the groups 
namely $\mathrm{A} 2 \mathrm{~B} 1$ vs. A2B2, A2B1 vs. A3B1, $\mathrm{A} 2 \mathrm{~B} 2$ vs. $\mathrm{A} 3 \mathrm{~B} 2, \mathrm{~A} 2 \mathrm{~B} 1$ vs. $\mathrm{A} 4 \mathrm{~B} 1, \mathrm{~A} 2 \mathrm{~B} 1$ vs. $\mathrm{A} 4 \mathrm{~B} 2, \mathrm{~A} 2 \mathrm{~B} 1$ vs. A5B1, A2B2 vs. A3B1, $\mathrm{A} 2 \mathrm{~B} 2$ vs. $\mathrm{A} 3 \mathrm{~B} 2, \mathrm{~A} 2 \mathrm{~B} 2$ vs. $\mathrm{A} 4 \mathrm{~B} 1, \mathrm{~A} 2 \mathrm{~B} 2$ vs. $\mathrm{A} 4 \mathrm{~B} 2$ and $\mathrm{A} 2 \mathrm{~B} 2$ vs. $\mathrm{A} 5 \mathrm{~B} 1$ were found to be non-significant while on comparison of mean scores A4B1 possessed high selfconfidence than their counterparts in schools. It is also tangible from the table 4 (Appendix D) that t-values 2.84 for female students having intuitive style (A2B2) and for female students having undifferentiated style (A5B2) is significant at 0.01 level directing to the implication that students of these groups in the selected schools differed significantly with respect to their selfconfidence and from the mean scores, it can be concluded that female students having undifferentiated style (A5B2) have lower self-confidence than the female students having intuitive style (A2B2). From the tvalue (0.12) given in Table 4 (Appendix D) , it depicts that male students having split style (A3B1) and for female students having split style (A3B2) do not differ significantly with respect to their self-confidence. So, the $\mathrm{t}$-value (0.34) for male students having split style (A3B1) and for male students having systematic style (A4B1) is not significant which highlights that these groups do not differ significantly.

From the Table 4 (Appendix D), the t-value (2.03) for male students having split style (A3B1) and for female students having systematic style (A4B2) is highly spot out at 0.05 levels and also be concluded that male students with split style (A3B1) have significantly higher self-confidence (25.55) than female students with systematic style (A4B2). The t-values 1.29, 0.16, 1.80 and 1.27 vide Table 4 (Appendix D) for groups A3B1 vs. A5B1, A3B2 vs. A4B1, A3B2 vs. $\mathrm{A} 4 \mathrm{~B} 2$ and $\mathrm{A} 3 \mathrm{~B} 2$ vs. A5B1 were found to be non-significant at 0.01 levels leading to the inference that these groups do not have very specific differences, when the results were seen in the context of the mean scores A4B1 reported higher self-confidence as compared to their respective counterparts. Anyway, the t-value of (5.95) from Table 4 (Appendix D) for male students having split style (A3B1) and for female students having undifferentiated style (A5B2) is significant at 0.01 levels. When comparing mean scores, it can be inferred that male students having split style (A3B1) have significantly higher self-confidence than female students having undifferentiated style (A5B2). Par with this, it can also highly reflect that the Table 4 (Appendix D), t-value for (5.25) female students having split style (A3B2) and for female students having undifferentiated style (A5B2) differ significantly at Level. It can also be said that female students having split style (A3B2) significantly higher self-confidence than students having undifferentiated style (A5B2).

So, the t-value (2.04) for male students having systematic style (A4B1) and for female students having systematic style ( A4B2) is found significant at 0.05 levels only. It also discovered that male students having systematic style (A4B1) are better than their counterparts with respect to their self-confidence and to this, t-value 1.40 vide table 4 (Appendix D) for male secondary school students having systematic style (A4B1) and for male secondary school students having undifferentiated style (A5B1) do not differ. According to the facts revealed from the Table 4 (Appendix D), tvalue of (5.54) for male students having systematic style (A4B1) and for female students having undifferentiated style (A5B2) is significant at 0.01 levels and when those findings were compared in the context of mean scores, the self-confidence for male students having systematic style (A4B1) was found to be higher than those with female students having undifferentiated style (A5B2). Anyway, the t-value 0.76 vide Table 4 (Appendix D) for female students having systematic style (A4B2) and for male students having undifferentiated style (A5B1) is not significant at 0.01 level which represents that these two groups do not have much differences. It was found that male 
students having undifferentiated style (A5B1) possess high self-confidence than female students having systematic style (A4B2) according to the meaningful context.

The t-value of (2.66) indicated in table 4 (Appendix D) for female students having systematic style (A4B2) and for female students having undifferentiated style (A5B2) is significant at 0.01 levels leading to an inference that the two groups differ significantly and can get a clear idea about the mean scores than female students belonging to systematic style (A4B2) have significantly higher self-confidence as compared to female students having undifferentiated style (A5B2). In the same way, it explores that the t-value (4.12) for male students having undifferentiated style (A5B1) and for female students having undifferentiated style (A5B2) is found to be significant at 0.01 level leading to the conclusion that students of these groups differ significantly with respect to their selfconfidence. On the other hand, the mean scores that inferred that male students having undifferentiated style (A5B1) have higher self-confidence than the female students having undifferentiated style (A5B2).

The interaction effect of cognitive style (A) and gender (B) on the self-confidence of school students in the selected schools have also been represented in the form of the line graph in Fig.3. (Appendix G) and in this figure, a $5 \times 2$ design interaction effect can be found. This leads to graphically when A1, A2, A3, A4, and A5 are marked on the Xaxis at any distance; and on $\mathrm{Y}$ ordinate a scale is taken for the mean values. Because there are ten cells, the mean of each cell is used to plot out the points and the mean $\mathrm{M} 11=33.40, \quad \mathrm{M} 21=25.89, \quad \mathrm{M} 31=25.55$, $M 41=24.61$ and M51=29.34 are marked to plotline B1. On par with, the means $\mathrm{M} 12=24.08, \quad \mathrm{M} 22=30.48, \quad \mathrm{M} 32=25.18$, $M 42=32.12$, and M52 $=40.86$ are marked for plotting the line B2. The interaction effect is normally depicted by the set of non-parallel lines. The lines are non-parallel and it is presented in the graph. Hence, the line graph represents a generous interaction effect of the two variables; Cognitive style and gender on the self-confidence of secondary school students in the Welimada Educational Zone.

\section{Conclusion}

According to the findings, students with a systematic cognitive style had considerably more self-confidence than students with an intuitive cognitive style. This is due to the fact that students with a systematic cognitive style are more aware of their learning process in school, and these students are associated with logical and rational behaviour changes, as well as the use of well-defined step-by-step approaches on learning, thinking, acting, performing, and the overall plan for problem-solving in their daily lives. It becomes one of the most important aspects of a student's life success. These pupils are very interested in when, why, what, and how a certain technique should be used to the problem-solving process. Students with an intuitive cognitive style, on the other hand, lack this capacity. Students' cognitive styles are supported and changed through teaching and learning techniques. In every situation, the instructor plays a critical role in assisting pupils in developing systematic cognitive patterns. This is applicable to any condition or circumstance. Teachers could simply detect the students' strong style patterns and behaviour in their classrooms, then use appropriate ways to meet the students' distinct cognitive style preferences. Between the curriculum designers and the teachers, there should be a link. That implies curriculum designers and classroom teachers must be aware of students' cognitive styles in order to employ appropriate strategies to promote meaningful learning in the classroom. When understanding the cognitive types of students, it is essential to determine the students' requirements and wants, as well as their priorities. 


\section{References}

Ahmadzade, L. \& Shojae, M. (2013). Investigating the relationship between cognitive style (field dependence / independence) and academic achievement in male and female students of Behbahan Islamic Azad University. Journal of life Science and Biomedicine, 3(3), 245 249.

Aseeri, M.M. (2000). An investigation of the relationship between students formed level of cognitive development, learning style and mathematics achievement in eleventh grade in Abha Saudi Arabia. Doctoral dissertation of Ohio University. Dissertation Abstract international; 61(7).

Beri, N. and Kumar (2016). Cognitive style of secondary school students in relation to Adversity Quotient. International Journall for Research in Social Science and Humanities Research, 2(1), 1-15.

Dowlatabadi, H. and Mehraganfar, M. (2014). The causal correlation between fielddependence/ Independence cognitive style and no vocabulary learning strategies among Iranian EFL learners. International Journal of Latest Research in Science and Technology, 3(4), 97-103.

Gupta and Suman (2017). Learning \& Thinking style as a major determinant of academic achievement among school students: An analytical study. Educational Quest: International Journal of Education and Applied Social Science, 8(3), 495-506.

https://doi.org/10.5958/22307311.2017.00098.8

Hall, L.A. (1993). A critical exploration of learning style preferences and the math achievement of chapter-I middle school students: Administrative and instructional implications (Eds.). Doctoral dissertation of Oklanoma State University. Dissertation Abstract International, 54(10).

Harvey, O. J., Hunt, D. E., \& Schroder, H. M. (1961). Conceptual systems and personality organization. New York: Wiley.

Igbo, J., Ikechukwu, R. F. E. V., \& Victoria, O. Conception Of Collaborative Learning In Secondary Schools: Relationships With Self-Efficacy Belief And Academic Achievement.

Idika, M. I. (2017). Influence of Cognitive Style and Gender on Secondary School Students' Achievement in and Attitude to Chemistry. Advances in Social Sciences Research Journal, 4(1). https://doi.org/10.14738/assrj.41.2585

Jantan, R. (2014). Relationship between students' cognitive style (field-dependent and independent cognitive style) with their mathematics achievement in primary school. International journal of Humanities Social Sciences and Education, 1 (10), 88-93.

Jena, P. C. (2013). Cognitive style of rural senior secondary school students in relation to their gender and stream. International Journal of Education and Psychological Research, 2(4), 37-44.

Maria Kozhevnikov, Mary Hegarty \& Richard E. Mayer (2002) Revising the VisualizerVerbalizer Dimension: Evidence for Two Types of Visualizers, Cognition and Instruction, 20:1, 4777.

https://doi.org/10.1207/S1532690XCI2001_3 
Messick, S. (1976). Personality consistencies in cognition and creativity. In S. Messick (Eds.), Individuality in learning (pp. 4 -23). San Francisco:Josse Bass.

Narayan, Hota (1995). Sex differences in mathematical and verbal reasoning ability among field independent and field dependent individuals. Journal of Community Guidance and Research, 12(3), 205-214.

Navarro, J. I., Aguilar, M., Alcalde, C., \& Howell, R. (1999). Relationship of Arithmetic Problem Solving and Reflective-Impulsive Cognitive Styles in Third-Grade Students. Psychological Reports, 85(1), 179-186. https://doi.org/10.2466/pr0.1999.85.1.179

Pandey, D.D. (2007). Manual of Self-Confidence Inventory for school students (PSCI). Agra: National Psychological Corporation.

Parashar, A. \& Aggarwal, A.K. (2013). Cognitive Style, Self-esteem and Socio-economic status determinants of Personality. Published Doctoral Thesis of education of Bundelkhand University.

Rao, V. (2014). A study of academic achievement in mathematics in relation to cognitive styles and attitude towards mathematics. Global Journal for Research Analysis, 3(1), 7-8.

Richard J. Riding \& Frank Pearson (1994) The Relationship between Cognitive Style and Intelligence, EducationalPsychology, 14:4,413-425.

https://doi.org/10.1080/0144341940140404

Riding, R. J., \& Sadler-Smith, E. (1997). Cognitive style and learning strategies: Some implications for training design. Instructional Journal of Training and Development, 1, 199208.

Eugene Sadler-Smith \& Beryl Badger (1998) Cognitive style, learning and innovation, Technology Analysis \& Strategic Management, 10:2, 247-266. https://doi.org/10.1080/09537329808524314

Sarasin, L. (2006). Learning Style Perspectives: Impact in the Classroom. Second Edition. Atwood Publication.

Singh, P. (2015). Interaction effect of brain hemispheric dominance and self concept on academic achievement in mathematics. Research Inventy: International Journal of Engineering and science, 5(9), 27-32.

Singh, V. (2017). Exploring the Relationship between cognitive Style and learning Style with Academic Achievement of Elementary School learners. Educational Quest: An International Journal of Education and Applied Social Sciences, 8, 413-419. 
Liyadipita L.A.M.H.P., KJM, 2021, 10 (Special Issue)

\section{Appendices}

\section{Appendix A}

Table 1: Mean's and Standard Deviations of Sub-Samples of 5x2 Design for Cognitive Style and Gender of Students with Respect to Self-Confidence

\begin{tabular}{|c|c|r|r|r|}
\hline Cognitive Style (A) & Gender (B) & N & \multicolumn{1}{|c|}{ Mean } & \multicolumn{2}{|c|}{ SD } \\
\hline \multirow{2}{*}{ Integrated Style (A1) } & Male (B1) & 32 & 18.96 & 16.73 \\
\cline { 2 - 5 } & Female (B2) & 35 & 32.60 & 16.39 \\
\hline \multirow{2}{*}{ Intuitive Style (A2) } & Male (B1) & 29 & 30.13 & 16.12 \\
\cline { 2 - 5 } & Female (B2) & 33 & 34.30 & 18.41 \\
\hline \multirow{2}{*}{ Split Style (A3) } & Male (B1) & 43 & 32.51 & 14.01 \\
\cline { 2 - 5 } & Female (B2) & 44 & 35.77 & 16.66 \\
\hline \multirow{2}{*}{ Systematic Style (A4) } & Male (B1) & 31 & 21.93 & 16.57 \\
\cline { 2 - 5 } & Female (B2) & 31 & 25.35 & 19.55 \\
\hline Undifferentiated Style (A5) & Male (B1) & 64 & 29.13 & 14.14 \\
\cline { 2 - 5 } & Female (B2) & 58 & 30.25 & 15.79 \\
\hline
\end{tabular}

\section{Appendix B}

Table 2: Summary of Two-Way ANOVA (5x 2 Factorial Designs) For Self-confidence of secondary school students with respect to cognitive Style and Gender

\begin{tabular}{|c|c|c|c|c|c|c|c|c|}
\hline $\begin{array}{c}\text { Integrated } \\
\text { (A1) }\end{array}$ & Systematic (A4) & $\mathbf{6 7}$ & $\mathbf{6 2}$ & $\mathbf{2 6 . 0 8}$ & $\mathbf{2 3 . 6 4}$ & $\mathbf{1 7 . 8 0}$ & $\mathbf{1 8 . 0 6}$ & $\mathbf{0 . 7 7}$ (NS) \\
\hline $\begin{array}{c}\text { Integrated } \\
\text { (A1) }\end{array}$ & $\begin{array}{c}\text { Undifferentiated } \\
\text { (A5) }\end{array}$ & 67 & 122 & 26.08 & 30.25 & 17.80 & 14.92 & 1.71 (NS) \\
\hline Intuitive (A2) & Split (A3) & 62 & 87 & 32.35 & 34.16 & 17.36 & 15.41 & $0.66(\mathrm{NS})$ \\
\hline Intuitive (A2) & Systematic (A4) & 62 & 62 & 32.35 & 23.64 & 17.36 & 18.06 & $2.73^{* *}$ \\
\hline Intuitive (A2) & $\begin{array}{c}\text { Undifferentiated } \\
\text { (A5) }\end{array}$ & 62 & 122 & 32.35 & 30.25 & 17.36 & 14.92 & $0.85(\mathrm{NS})$ \\
\hline Split (A3) & Systematic (A4) & 87 & 62 & 34.16 & 23.64 & 15.41 & 18.06 & $3.82^{* *}$ \\
\hline $\begin{array}{c}\text { Split (A3) } \\
\text { Undifferentiated } \\
\text { (A5) }\end{array}$ & 87 & 122 & 34.16 & 30.25 & 15.41 & 14.92 & $0.52(\mathrm{NS})$ \\
\hline $\begin{array}{c}\text { Systematic } \\
\text { (A4) }\end{array}$ & $\begin{array}{c}\text { Undifferentiated } \\
\text { (A5) }\end{array}$ & 62 & 122 & 23.64 & 30.25 & 18.06 & 14.92 & $2.64^{* *}$ \\
\hline
\end{tabular}


Liyadipita L.A.M.H.P., KJM, 2021, 10 (Special Issue)

\section{Appendix C}

Table 3: 'T'-Values for the Mean Scores of Self- Confidence of Students Cognitive students

\begin{tabular}{|c|c|c|c|c|}
\hline Sources of Variance & Df & Sum of Squares (SS) & $\begin{array}{c}\text { Mean Sum of } \\
\text { Squares (MSS) }\end{array}$ & F-Ratios \\
\hline \multicolumn{5}{|l|}{ Main Effects } \\
\hline A (Cognitive Style) & 4 & 5434.682 & 1358.671 & $5.16 * *$ \\
\hline $\mathrm{B}$ (Gender) & 1 & 1863.930 & 1863.930 & $7.07 * *$ \\
\hline \multicolumn{5}{|c|}{ Double Interaction Effects } \\
\hline $\mathrm{A} \times \mathrm{B}$ Interaction & 4 & 2687.570 & 671.892 & $2.55 *$ \\
\hline Between Cells & 9 & 9276.171 & 263.320 & \\
\hline Within cells & 390 & 102694.607 & .............. & \\
\hline Total & 399 & & & \\
\hline
\end{tabular}

\section{Appendix D}

Table 4: ' $T$ '-Values for Mean Scores of Self-Confidence of Secondary School Students in Welimada Educational Zone for Different Groupls of Cognitive Style (A) x Gender

(B)

\begin{tabular}{|c|c|c|c|c|c|c|c|r|}
\hline $\begin{array}{c}\text { Sr. } \\
\text { No. }\end{array}$ & Groups & \multicolumn{2}{|c|}{$\mathrm{N}$} & \multicolumn{2}{c|}{ Mean } & \multicolumn{2}{c|}{ SD } & $\begin{array}{c}\text { 'T'- } \\
\text { Values }\end{array}$ \\
\hline 1. & A1B1vs.A1B2 & 32 & 35 & 33.40 & 24.08 & 20.28 & 14.12 & $2.19^{*}$ \\
\hline 2. & A1B1vs.A2B1 & 32 & 29 & 33.40 & 25.89 & 20.28 & 17.26 & $1.54(\mathrm{NS})$ \\
\hline 3. & A1B1 vs. A2B2 & 32 & 33 & 33.40 & 30.48 & 20.28 & 21.08 & $0.56(\mathrm{NS})$ \\
\hline 4. & A1B1 vs. A3B1 & 32 & 43 & 33.40 & 25.55 & 20.28 & 11.38 & $2.12^{*}$ \\
\hline 5. & A1B1 vs. A3B2 & 32 & 44 & 33.40 & 25.18 & 20.28 & 16.39 & $1.95(\mathrm{NS})$ \\
\hline 6. & A1B1 vs. A4B1 & 32 & 31 & 33.40 & 24.61 & 20.28 & 12.06 & $2.08^{*}$ \\
\hline 7. & A1B1 vs. A4B2 & 32 & 31 & 33.40 & 32.12 & 20.28 & 16.47 & $0.27(\mathrm{NS})$ \\
\hline 8. & A1B1 vs. A5B1 & 32 & 64 & 33.40 & 29.34 & 20.28 & 16.80 & $1.04(\mathrm{NS})$ \\
\hline 9. & A1B1 vs. A5B2 & 32 & 58 & 33.40 & 40.86 & 20.28 & 13.70 & $2.07 *$ \\
\hline 10. & A1B2 vs. A2B1 & 35 & 29 & 24.08 & 25.89 & 14.12 & 17.26 & $0.46(\mathrm{NS})$ \\
\hline 11. & A1B2 vs. A2B2 & 35 & 33 & 24.08 & 30.48 & 14.12 & 21.08 & $1.47(\mathrm{NS})$ \\
\hline 12. & A1B2 vs. A3B1 & 35 & 43 & 24.08 & 25.55 & 14.12 & 11.38 & $0.51(\mathrm{NS})$ \\
\hline 13. & A1B2 vs. A3B2 & 35 & 44 & 24.08 & 25.18 & 14.12 & 16.39 & $0.31(\mathrm{NS})$ \\
\hline 14. & A1B2 vs. A4B1 & 35 & 31 & 24.08 & 24.61 & 14.12 & 12.06 & $0.16(\mathrm{NS})$ \\
\hline 15. & A1B2 vs. A4B2 & 35 & 31 & 24.08 & 32.12 & 14.12 & 16.47 & $2.13 *$ \\
\hline 16. & A1B2 vs. A5B1 & 35 & 64 & 24.08 & 29.34 & 14.12 & 16.80 & $1.57(\mathrm{NS})$ \\
\hline 17. & A1B2 vs. A5B2 & 35 & 58 & 24.08 & 40.86 & 14.12 & 13.70 & $5.65 * *$ \\
\hline 18. & A2B1 vs. A2B2 & 29 & 33 & 25.89 & 30.48 & 17.26 & 21.08 & $0.93(\mathrm{NS})$ \\
\hline 19. & A2B1 vs. A3B1 & 29 & 43 & 25.89 & 25.55 & 17.26 & 11.38 & $1.00(\mathrm{NS})$ \\
\hline 20. & A2B1 vs. A3B2 & 29 & 44 & 25.89 & 25.18 & 17.26 & 16.39 & $0.17(\mathrm{NS})$ \\
\hline 21. & A2B1 vs. A4B1 & 29 & 31 & 25.89 & 24.61 & 17.26 & 12.06 & $0.33(\mathrm{NS})$ \\
\hline 22. & A2B1 vs. A4B2 & 29 & 31 & 25.89 & 32.12 & 17.26 & 16.47 & $1.43(\mathrm{NS})$ \\
\hline 23. & A2B1 vs. A5B1 & 29 & 64 & 25.89 & 29.34 & 17.26 & 16.80 & $0.90(\mathrm{NS})$ \\
\hline
\end{tabular}


Liyadipita L.A.M.H.P., KJM, 2021, 10 (Special Issue)

\begin{tabular}{|l|l|l|l|l|l|l|r|r|}
\hline 24. & A2B1 vs. A5B2 & 29 & 58 & 25.89 & 40.86 & 17.26 & 13.70 & $4.39^{* *}$ \\
\hline 25. & A2B2 vs. A3B1 & 33 & 43 & 30.48 & 25.55 & 21.08 & 11.38 & $1.30(\mathrm{NS})$ \\
\hline 26. & A2B2 vs. A3B2 & 33 & 44 & 30.48 & 25.18 & 21.08 & 16.39 & $1.24(\mathrm{NS})$ \\
\hline 27. & A2B2 vs. A4B1 & 33 & 31 & 30.48 & 24.61 & 21.08 & 12.06 & $1.35(\mathrm{NS})$ \\
\hline 28. & A2B2 vs. A4B2 & 33 & 31 & 30.48 & 32.12 & 21.08 & 16.47 & $0.34(\mathrm{NS})$ \\
\hline 29. & A2B2 vs. A5B1 & 33 & 64 & 30.48 & 29.34 & 21.08 & 16.80 & $0.29(\mathrm{NS})$ \\
\hline 30. & A2B2 vs. A5B2 & 33 & 58 & 30.48 & 40.86 & 21.08 & 13.70 & $2.84^{* *}$ \\
\hline 31. & A3B1 vs. A3B2 & 43 & 44 & 25.55 & 25.18 & 11.38 & 16.39 & $0.12(\mathrm{NS})$ \\
\hline 32. & A3B1 vs. A4B1 & 43 & 31 & 25.55 & 24.61 & 11.38 & 12.06 & $0.34(\mathrm{NS})$ \\
\hline 33. & A3B1 vs. A4B2 & 43 & 31 & 25.55 & 32.12 & 11.38 & 16.47 & $2.03^{*}$ \\
\hline 34. & A3B1 vs. A5B1 & 43 & 64 & 25.55 & 29.34 & 11.38 & 16.80 & $1.29(\mathrm{NS})$ \\
\hline 35. & A3B1 vs. A5B2 & 43 & 58 & 25.55 & 40.86 & 11.38 & 13.70 & $5.95^{* *}$ \\
\hline 36. & A3B2 vs. A4B1 & 44 & 31 & 25.18 & 24.61 & 16.39 & 12.06 & $0.16(\mathrm{NS})$ \\
\hline 37. & A3B2 vs. A4B2 & 44 & 31 & 25.18 & 32.12 & 16.39 & 16.47 & $1.80(\mathrm{NS})$ \\
\hline 38. & A3B2 vs. A5B1 & 44 & 64 & 25.18 & 29.34 & 16.39 & 16.80 & $1.27(\mathrm{NS})$ \\
\hline 39. & A3B2 vs. A5B2 & 44 & 58 & 25.18 & 40.86 & 16.39 & 13.70 & $5.25^{* *}$ \\
\hline 40. & A4B1 vs. A4B2 & 31 & 31 & 24.61 & 32.12 & 12.06 & 16.47 & $2.04^{*}$ \\
\hline 41. & A4B1 vs. A5B1 & 31 & 64 & 24.61 & 29.34 & 12.06 & 16.80 & $1.40(\mathrm{NS})$ \\
\hline 42. & A4B1 vs. A5B2 & 31 & 58 & 24.61 & 40.86 & 12.06 & 13.70 & $5.54^{* *}$ \\
\hline 43. & A4B2 vs. A5B1 & 31 & 64 & 32.12 & 29.34 & 16.47 & 16.80 & $0.76(\mathrm{NS})$ \\
\hline 44. & A4B2 vs. A5B2 & 31 & 58 & 32.12 & 40.86 & 16.47 & 13.70 & $2.66^{* *}$ \\
\hline 45. & A5B1 vs. A5B2 & 64 & 58 & 29.34 & 40.86 & 16.80 & 13.70 & $4.12^{* *}$ \\
\hline
\end{tabular}

Appendix E

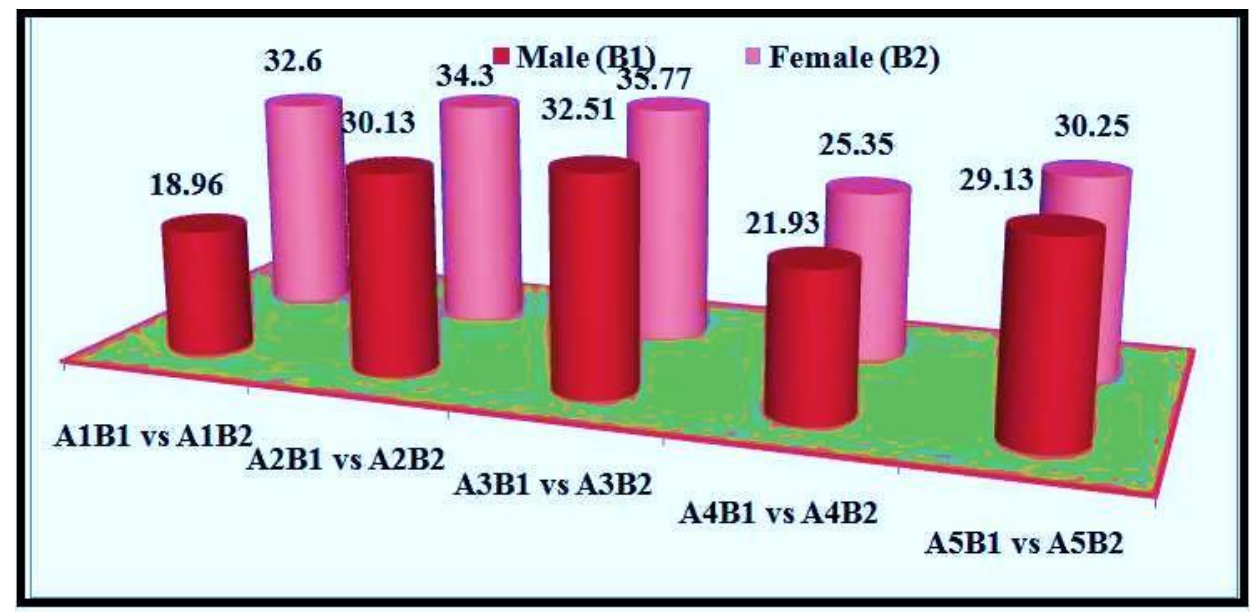

Figure 1: Mean Scores of Sub Samples of 5x2 Design for Self-Confidence of Secondary School Students with respect to Cognitive Style and Gender

\section{Appendix F}




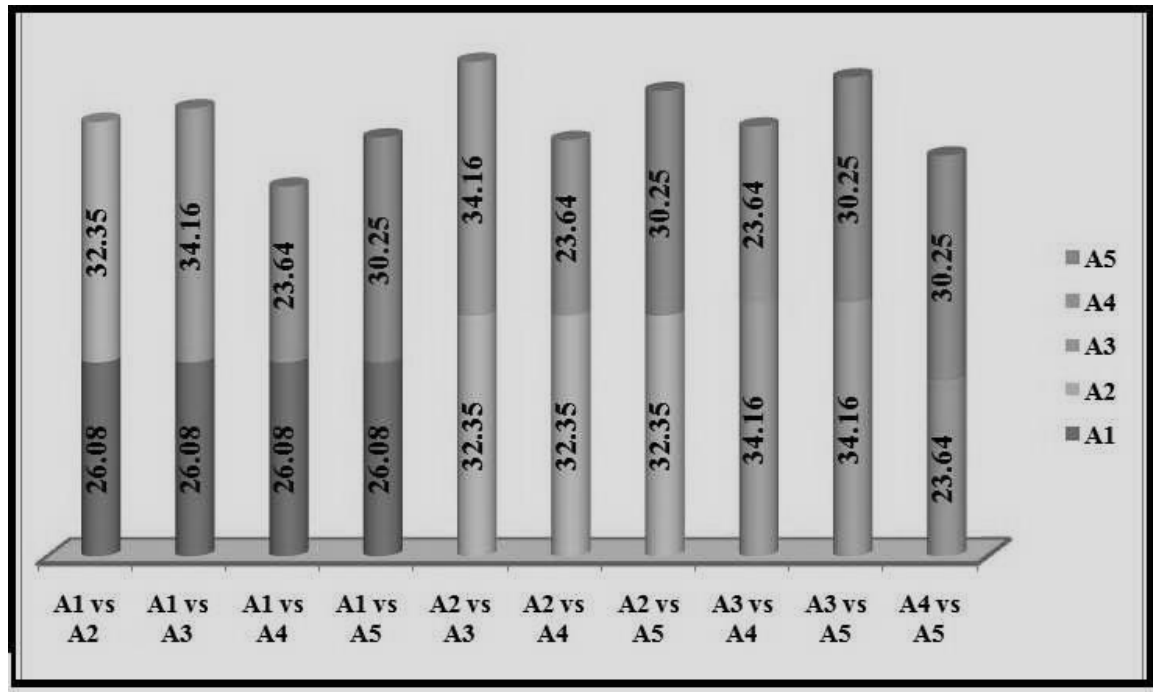

Figure 2: Main Effects of Cognitive Style on Self-Confidence of Secondary School Students (Mean Scores) Gender (B)

\section{Appendix G}

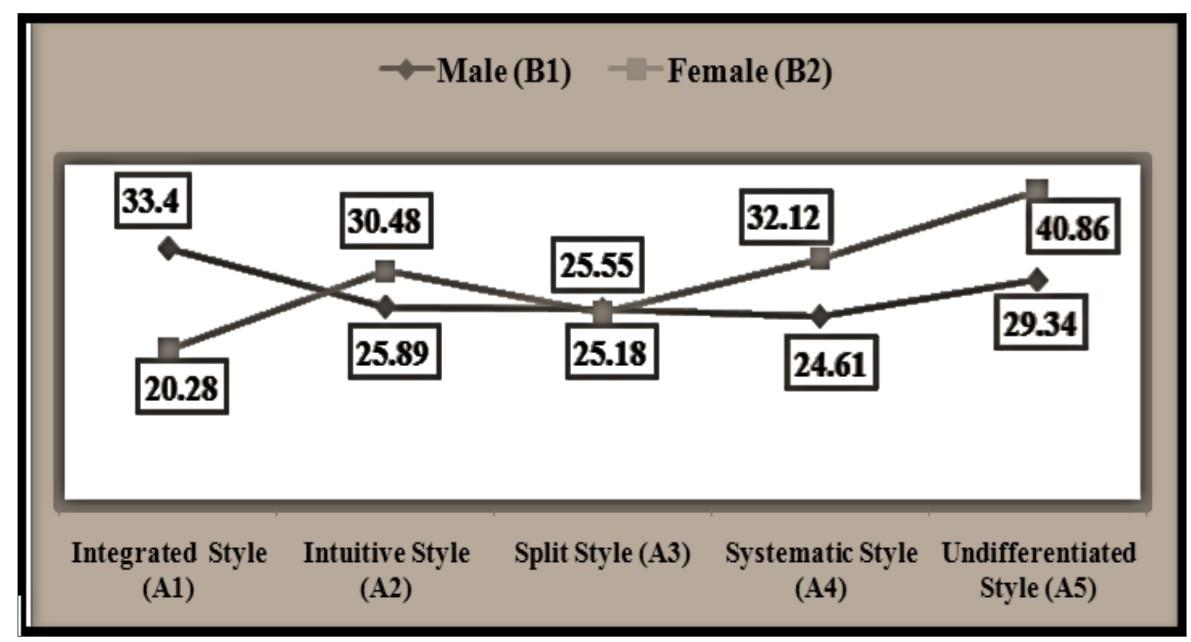

Figure 3: Interaction Effect of Cognitive Style (A) x Gender (B) on Self Confidence of secondary school students 